\title{
Feasibility of combined treatment for type III spinal muscular atrophy: a pilot study
}

\author{
Nataliia Sych' \\ Mariya Klunnyk' \\ Iryna Matiyashchuk' \\ Mariya Demchuk' \\ Olena Ivankova' \\ Andriy Sinelnyk' \\ Khrystyna Sorochynska ${ }^{2}$ \\ Marina Skalozub ${ }^{3}$ \\ 'Clinical Department, ${ }^{2}$ Stem Cells \\ Bank, ${ }^{3}$ Laboratory and Biotechnology \\ Department, Cell Therapy Center \\ EmCell, Kyiv, Ukraine
}

This article was published in the following Dove Press journal: Journal of Neurorestoratology

26 September 2017

Number of times this article has been viewed

Objective: To find solutions and improve methods of therapy for patients suffering from type III spinal muscular atrophy (SMA-III) by way of a combination of conventional treatment (medicines, physiotherapy) and fetal stem cells (FSCs) transplantation using suspensions extracted from stem cells of fetal liver and brain of human embryos.

Materials and methods: Our study included 7 children suffering from SMA-III, including 5 boys and 2 girls, aged from 3 to 12 years who were allocated into the main group (MG). SMA children in the MG were administered fetal stem cell preparations, mainly suspensions which contained fetal cells of human liver and fetal brain along with standard treatment (treatment by use of medicines if required and physiotherapy). The control group (CG) included 6 children 3 boys and 3 girls aged from 3.5 to 13 years.

Results: The authors proved effectiveness and safety of treatment using FSCs for patients with SMA-III. Improvement of forced vital capacity of lungs and forced expiratory volume per 1 second was characteristic for the patients of the MG, starting from the period of observation at 6 months after FSCs transplantation. In patients from the CG, such values revealed characteristic improvement at 12 months after FSCs treatment. Significant reductions of alanina aminotransferase, aspartate aminotransferase, creatine phosphokinase, and lactate dehydrogenase ranges have been recorded in the patients of the MG at 6 months after treatment with FSCs. Such values show a significant reduction at 12 months after treatment.

Conclusion: FSCs use in complex treatment of patients with SMA results in stable disease compensation, improvement of laboratory results, and improved ranges of forced vital capacity and forced expiratory volume in 1 second.

Keywords: fetal stem cells, forced expiratory volume per 1 second, forced vital capacity of the lungs, type III spinal muscular atrophy

\section{Introduction}

Spinal muscular atrophy (SMA) is an autosomal recessive, proximal spinal amyotrophy that belongs to a heterogeneous group of hereditary diseases and persists with affection or loss of anterior horn cells in the spinal cord. ${ }^{1}$

Pathogenesis of SMA is due to errors in the gene encoding survival motor neuron $(S M N)$ protein, which is expressed in all tissues of the organism, predominantly those in the motor neurons of the spinal cord. Within cytoplasm and the nucleus of somatic cells, $S M N$ could be associated with another protein - SIP1, localized in hemes which are special corpuscles of the nucleus. Such proteins are necessary for mRNA regeneration and transformation, because the presence of SMN mutation in the gene leads to disruption of these processes in the patients. ${ }^{1,2}$
Correspondence: Nataliia Sych

Clinical Department, Cell Therapy

Center EmCell, 37 A Syretska str, 04073

Kyiv, Ukraine

Tel +380688898989

Email infocenter@emcell.com
Journal of Neurorestoratology 2017:5 167-173

167

Dovepress $f$ in $\Delta$

(c) (1) (8) $\odot 2017$ Sych et al. This work is published and licensed by Dove Medical Press Limited. The full terms of this license are available at https:///www.dovepress.com/terms.

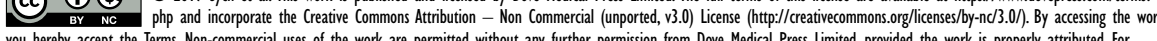
you hereby accept the Terms. Non-commercial uses of the work are permitted without any further permission from Dove Medical Press Limited, provided the work is properly attributed. For permission for commercial use of this work, please see paragraphs 4.2 and 5 of our Terms (https://www.dovepress.com/terms.php). 
Affection of cross-striated muscles of legs, head, and neck is a characteristic sign of spinal muscular atrophies. Such patients present with general disturbances of voluntary movements - crawling, walking, poising the head, and swallowing. Muscles of arms are usually not affected. Preserved sensitivity along with absence of psychomotor development is characteristic for the patients.

Damage of motor neurons and, consequently, motor musculature causes a variety of clinical symptoms in the disease. Patients with SMA also suffer from growing muscular weakness and atrophy; severe disturbances of posture (kyphoscoliosis); and disruption of breathing and motor functions. Sensitivity, both psychic and intellectual sphere, is also fully preserved in the patients. ${ }^{2,3}$

Currently, there are no methods of treatment for SMA that could change this disease course in the patients. ${ }^{4}$ Maintenance therapy consists in correction of symptoms of this disease along with prevention of future complications. The most frequent measures in such patients include a supply of necessary consumption of nutrients, maintenance of breathing, physical exercising, and auxiliary aid, which could be performed at terminal stages of the disease. Despite the fact that all standards of care for the patients with SMA have already been established, one must also consider a necessity of renovation and specification of different measures to help such patients. Physiotherapy and occupational therapy programs can help both children and adult patients learn how to use preserved muscular functions in the best way as well as help define the most effective approach to activities of daily living for such patients. Presently, different existing appliances could help even the youngest SMA patients to get acquainted with the environment. Standing frames, babywalkers, various kinds of electric gurneys or push-carts, fiber glass casts - all of them could be helpful for SMA patients by aiding them to keep an upright stance or by helping them with ability to move.

SMA disease is considered to be incurable; however, multiple clinical studies have been launched all over the world, an ambitious project toward the end of curing the disease. Such research works are devoted to different methods targeted to increase protein binding with SMN gene: with the help of replacement or rectification on mutations in SMN1 gene, by means of modulation of negative and positive regulators for gene splicing, and by inclusion of the 7th exon into SMN2 gene. Also, this might be possible due to elevated promoter activity in SMN2 gene or by way of stabilization/protection of a full-length protein within SMN and SMN7. In view of augmentation of SMN protein, which is mandatory in therapy tactics, it is important to define its minimal amount necessary for cells survival and proper functioning. In conformity with the results of a preclinical study, in order to maintain SMN gene phenotype in the patients who have two replications of SMN2 gene, it is necessary to promote $25 \%$ increase in concentration of full-length SMN protein. ${ }^{4}$

At present, there are no medicines that could help to cure or stop SMA disease progress in the patients. Clinical studies of the medical drug (nusinersen) give great expectations for progress in treatment of SMA patients.

Nusinersen is regarded as antisense oligonucleotide. Antisense oligonucleotides belong to synthetic variants of nucleic acids that bind to particular sites of RNA and are capable of disrupting expression of the selected genes. This is the principal mechanism of therapy when using antisense oligonucleotide - switching off/inhibiting the synthesis of proteins taking part in genetic disease development. At present, there are several clinical trials which are targeted at treatment, prevention, and inhibition of neurodegenerative diseases. Antisense oligonucleotides are regarded as the main hope of doctors worldwide. ISIS-SMNRx - a medicine manufactured by ISIS Pharma for treatment of SMA - one of the severe neuromuscular diseases that remains as one of the principal causes of mortality in children. ISIS-SMNRx had been developed for therapy of all childhood types of SMA with the help of gene splicing from the heterogeneous SMN2 gene which causes increased production of functional SMN protein. ${ }^{5}$

Several highly efficient screening tests to control binding could constitute a SMN gene expression pattern. Besides regulation of SMN2 gene expression, scientists also suggested other alternative methods - for instance, use of stem cells, neuroprotective molecules, and compounds which can increase muscles power in the patients under study. It is worth mentioning that neuroprotective causes for growth as well as muscular augmenters can result in unfavorable systemic reactions in the patients, and their true effects are also unproven at present. At this time, approximately 17 scientific studies (both preclinical and clinical) have been devoted to studying different methods of therapy for the patients with SMA. ${ }^{6}$

Application of stem cells treatment for the patients suffering from SMA could be regarded as a prospective direction in science and medical practice. Sych et $\mathrm{al}^{7}$ proved the influence of fetal stem cells (FSCs) on functional capacity and life quality of patients suffering from Duchenne muscular dystrophy as well as showed the potential of FSCs to prevent Duchenne muscular dystrophy-related complications and inhibit fast disease progression. In addition, one more study has been conducted with the goal of studying efficacy 
and safety of FSCs use in patients with amyotrophic lateral sclerosis (ALS). Scientists confirmed that stem cell therapy leads to a decrease in ALS-related complications and simultaneously contributes to slowing down respiratory insufficiency progression that commonly appears in ALS patients. ${ }^{8}$

Our main task was to bring all existing approaches to treatment of the patients with SMA-III up to date by means of a combined use of conventional therapy (medical, physiotherapy) in combination with FSC preparations containing suspensions of isolated human stem cells, in particular the cells extracted from fetal liver and brain.

\section{Materials and methods}

Seven children diagnosed with SMA-III participated in this study, including 5 boys and 2 girls aged from 3 to 12 years, and they were allocated in the main group (MG). Children in the MG were administered FSC suspensions of isolated human stem cells, specifically stem cells extracted from fetal liver and brain in combination with standard treatment (medicines if necessary and physiotherapy).

The control group (CG) included 6 children ( 3 boys and 3 girls) whose age ranged from 3.5 to 13 years.

SMA diagnosis was confirmed by analysis of the results of imaging studies, past history, positive findings of electroneuromyography, laboratory analyses (alanine aminotransferase [ALT], aspartate aminotransferase [AST], creatine phosphokinase $[\mathrm{CPK}]$, and lactate dehydrogenase $[\mathrm{LDH}])$, genetic testing, and biopsy results. In $76.92 \%$ of cases, diagnosis was confirmed by genetic test findings, whereas in over $92.31 \%$ of patients it was established by the results of muscle biopsy.

Serum ALT, AST, CPK, and LDH levels were calculated by means of enzyme-linked immunoassay. ${ }^{9}$

Lung ventilation capacity was measured using a BTL-08 Spiro spirograph (CardioPoint ${ }^{\circledR}$, Slovakia, Bratislava, 2010) in accordance with the approved standards, ${ }^{10}$ and arterial oxyhemoglobin $\left(\mathrm{SpO}_{2}\right)$ rates were assessed by means of a pulse oxymeter (YX300 Armed, Moscow, Russia, 2011).

\section{Stem cells procedure}

Two preparations were readily made in the form of a suspension containing cryopreserved stem cells - one with inclusion of stem cells extracted from human fetal liver, and the other containing stem cells separated from fetal brain. For this purpose, within the premises of the operation room fetal material was extracted in conformity with the rules of aseptics and anticeptics; in particular, tissues of fetal liver and brain (human embryos from 6 to 9 weeks of gestation) were obtained as a result of medical abortion on termination of pregnancy by a woman due to social reasons and in absence of developmental pathology or infection in the fetus. As was mandatory, informed consent was obtained from the woman prior to embryo material withdrawal. Extracted fetal tissues were placed into transport media with Hanks' balanced salt solution. In this sterile environment, tissues are further separated and homogenized in Hanks' solution. Later, all obtained suspensions were exposed to filtration and cryopreservation. Dimethyl sulfoxide is also used as a cryoprotectant. In addition, readymade suspensions are placed into the cryovials in volumes ranging from 0.1 to $1.0 \mathrm{~mL}$. Programmed cryopreservation of FSCs suspensions is performed with the help of a chamber of a software-based freezer in accordance with specially adjusted program. Suspensions containing human stem cells separated from fetal liver and brain were stored in liquid nitrogen at the cryobank at a temperature of $-196^{\circ} \mathrm{C}$.

For the purpose of treatment safety, both women donors and readymade fetal stem cells were tested for parasites and mycotic, bacterial, and viral infections such as human immunodeficiency virus 1 and 2, hepatitis B virus, hepatitis $\mathrm{C}$ virus, rubella, cytomegalovirus, herpes simplex virus 1 and 2, Epstein-Barr virus, syphilis (Treponema pallidum), toxoplasmosis (Toxoplasma gondii), Mycoplasma genitalium, Ureaplasma urealyticum, Ureaplasma parvum, and Chlamydia trachomatis.

Directly before administration, suspensions were removed from liquid nitrogen and placed into a water bath for thawing at temperature $+37^{\circ} \mathrm{C}$, continued until liquid phase is reached. All further manipulations were performed at room temperature adhering strictly to aseptic conditions. The time duration for which defrosted FSCs suspensions (human fetal liver and brain) can be maintained at indoor temperature should not exceed 10 minutes.

The stem cell procedure consisted of transplantation of the suspension containing cryopreserved FSCs following conventional premedication by use of infusions with diphenylhydramine $10 \mathrm{mg}$ (Darnitsa Pharmaceutical, Kyiv, Ukraine) and prednisone $15 \mathrm{mg}$ (Darnitsa Pharmaceutical) on treatment day 1 and a specially prepared solution on day 2 . During the 1st day, children with SMA allocated to the MG were administered intravenous drip-feed infusion containing suspended fetal liver stem cells in a volume of $0.5-3.5 \mathrm{~mL}$ with a number of nucleated cells ranging from 1.0 to $54 \times 10^{6} /$ $\mathrm{mL}$ and values of $\mathrm{CD} 34+$ progenitor cells from 1 up to $20 \times 10^{5} / \mathrm{mL}$; colony-forming units in the suspensions with fetal liver stem cells constituted from 0.03 to $0.93 \times 10^{6} / \mathrm{mL}$. On treatment day 2 , fetal brain stem cells were transplanted subcutaneously to an overall amount ranging from 1 to $3 \mathrm{~mL}$.

Neurological assessment and laboratory tests (CPK, AST, ALT, and LDH levels) along with instrumental examinations 
were performed before fetal stem cell treatment (FSCT) and at 6 and 12 months after therapy. Our study was enrolled into the public register at the Ministry of Education and Science of Ukraine. Approval was received from the local ethics committee at Kyiv City Clinical Hospital for Accident and Emergency Care. Prior to FSCT, parents of the patients signed informed consent for treatment by use of FSCs.

\section{Statistical analysis}

Average results and their standard deviations were calculated by means of defining a significant difference using Statistika 12.0 software program (StatSoft Inc., Tulsa, Oklahoma, USA) and Student's $t$-criteria. Differences were regarded as statistically significant if $p<0.05$.

\section{Results}

All patients in the study showed early posttransplantation improvements: better sleep and appetite were presented. After administration of a suspension containing cryopreserved stem cells obtained from fetal liver, there was no evidence of posttransplantation complications, and no side effects or "graft-versus-host" reactions were recorded by the patients.

Functional assessment of the lungs was conducted in the patients: forced vital capacity (FVC) and forced expiratory volume in 1 second $\left(\mathrm{FEV}_{1}\right)$ results were controlled. After treatment, the patients reported improved functional lungs capacity (Table 1 ).

Patients in the MG reported a significant improvement in all indices at 6 months after treatment: FVC, \% (96.19 \pm 2.1$)$, $\mathrm{FEV}_{1}, \%(97.41 \pm 3.2)$, compared to the values at baseline FVC, \% ( 77.35+3.1), FEV1, \% ( 78.22+2.5), $p<0.05$. This improvement was remarkable for the patients, and this even persisted at 12 months after treatment - FVC, \% (98.24 \pm 5.1$)$, $\mathrm{FEV}_{1}, \%$ (99.24 \pm 2.6$), \mathrm{SpO}_{2}, \%$ (98.52 \pm 0.21$), p<0.05$. Simultaneously, a similar improvement was significantly seen in CG patients at 1 year after the beginning of treat- ment: (FVC, \% (91.15+2.1), $\mathrm{FEV}_{1}, \%$ (90.15+2.2), $\mathrm{SpO}_{2}$, $\%(95.47 \pm 0.17))$ if compared to the results before treatment

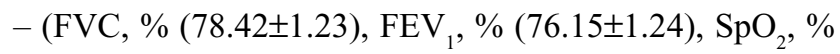
$(91.59 \pm 0.16)), p<0.05$.

In order to assess muscular weakness that is especially remarkable for such a category of patients and, most probably, remains as a sequel of cells myolysis, the following range of tests for blood diagnostics was performed in the patients under study: ALT, AST, CPK, and LDH levels. These parameters do not really bear a specific diagnostic value; however, such levels increase could be a sign of necrosis of muscle tissue.

FSCT resulted in significant ALT level decrease in the $\mathrm{MG}$ at 6 months after treatment $(0.88 \pm 0.11 \mathrm{U} / \mathrm{L}$ versus $1.39 \pm 0.21 \mathrm{U} / \mathrm{L} ; p<0.05)$. AST ranges were also reduced by $(0.791 \pm 0.05 \mathrm{U} / \mathrm{L}$ versus $0.88 \pm 0.06 \mathrm{U} / \mathrm{L})$ at 6 months after FSCT; however, such a decrease was not significant $(p<0.05)$. At 12 months after the FSCT, serum ALT and AST values were $0.68 \pm 0.22 \mathrm{U} / \mathrm{L}$ and $0.54 \pm 0.03 \mathrm{U} / \mathrm{L}$, respectively, and this confirms a significant decrease $(p<0.05)$ compared with the results measured at baseline (Figure 1).

The situation in the CG patients was different - at 12 months after the treatment, significant ALT and AST level reduction was reported: $(0.79 \pm 0.17 \mathrm{U} / \mathrm{L}$ and $0.73 \pm 0.04 \mathrm{U} / \mathrm{L}$, respectively) versus baseline: $(1.32 \pm 0.11 \mathrm{U} / \mathrm{L}$ and $1.01 \pm 0.05$ $\mathrm{U} / \mathrm{L}$, respectively); $p<0.05$.

Investigations on such enzymes as CPK and LDH were also conducted for the patients. Their high ranges in blood serum may be a result of myolysis of muscles, which is not regarded as a $100 \%$ characteristic sign to establish a diagnosis of SMA-III. Patients with SMA-III recorded a significant reduction of CPK starting from the 6th month compared to the results prior to treatment $(2583.4 \pm 49.22 \mathrm{U} / \mathrm{L}$ before FSCT;

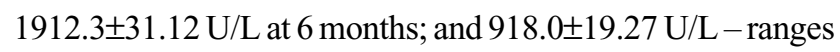
at 12 months after FSCs administration), $p<0.05$. The average score of $\mathrm{LDH}$ was $26.4 \pm 18.04 \mathrm{U} / \mathrm{L}$ prior to treatment. At

Table I FVC, $\mathrm{FEV}_{1}$, and $\mathrm{SpO}_{2}$, \% values: a comparison between patients in MG and CG before FSCT and at 6 and 12 months after FSCs therapy

\begin{tabular}{|c|c|c|c|c|c|c|}
\hline \multirow[t]{2}{*}{ Time period } & \multicolumn{3}{|l|}{ MG } & \multicolumn{3}{|l|}{ CG } \\
\hline & FVC, $\%$ & FEV $_{1}, \%$ & $\mathrm{SpO}_{2}, \%$ & FVC,\% & FEV $_{1}, \%$ & $\mathrm{SpO}_{2}, \%$ \\
\hline Before treatment & $77.35 \pm 3.1$ & $78.22 \pm 2.5$ & $92.61 \pm 0.18$ & $78.42 \pm 1.23$ & $76.15 \pm 1.2^{*}$ & $91.59 \pm 0.16$ \\
\hline At 6 months & $96.19 \pm 2.1 *$ & $97.4 I \pm 3.2 *$ & $93.41 \pm 0.15$ & $82.14 \pm 1.4$ & $81.18 \pm 3.2$ & $92.91 \pm 0.21$ \\
\hline At 12 months & $98.24 \pm 5.1 * *$ & $99.24 \pm 2.6 * *$ & $98.52 \pm 0.21^{* *}$ & $91.15 \pm 2.1 * *$ & $90.15 \pm 2.2^{* *}$ & $95.47 \pm 0.17^{* *}$ \\
\hline
\end{tabular}

Notes: ${ }^{*} p<0.05$ - significant improvement before treatment and at 6 months after FSCs transplantation. ${ }^{* *} p<0.05-$ significant improvement before treatment and at 12 months after FSCs administration.

Abbreviations: CG, control group; $\mathrm{FEV}_{1}$, forced expiratory volume in I second; FSCT, fetal stem cell treatment; FVC, forced vital capacity; MG, main group; SpO, peripheral capillary oxygen saturation. 
6 months, our patients revealed a tendency to have decreased LDH levels $(379 \pm 21.03 \mathrm{U} / \mathrm{L})$. At 12 months, this parameter was significantly lower, $284 \pm 19.11 \mathrm{U} / \mathrm{L}, p<0.05$. The patients in the CG reported a significant reduction of $\mathrm{LDH}$ levels, which significantly decreased over 1 year after treatment (2621.4 $\pm 47.23 \mathrm{U} / \mathrm{L}$ before treatment, $2312.3 \pm 38.11 \mathrm{U} / \mathrm{L}-$ at 6 months and $1652.0 \pm 17.23 \mathrm{U} / \mathrm{L}$ - at 12 months for values of $\mathrm{CPK}, p<0.05)$. With regard to $\mathrm{LDH}$, we observed the following tendency: $\mathrm{LDH}$ ranges were $538.5 \pm 12.09 \mathrm{U} / \mathrm{L}$ prior to treatment, $498 \pm 23.03 \mathrm{U} / \mathrm{L}$ at 6 months after FSCs administration, and $401 \pm 13.07 \mathrm{U} / \mathrm{L}$ in the patients at 12 months after FSCT $(p<0.05)$ (Figures 2 and 3$)$.

Among the goals of this study, we did not particularly evaluate FSCs effects on SMA disease. Nevertheless, one can probably emphasize two main mechanisms by which FSCs have an effect on the above disease: 1) differentiation to form myogenic cells and 2) stem cells promoting a trophic effect.

The efficacy of several cell types was demonstrated on the models of small animal. ${ }^{11}$ Researchers have shown that high-speed magnetic resonance imaging can be used to

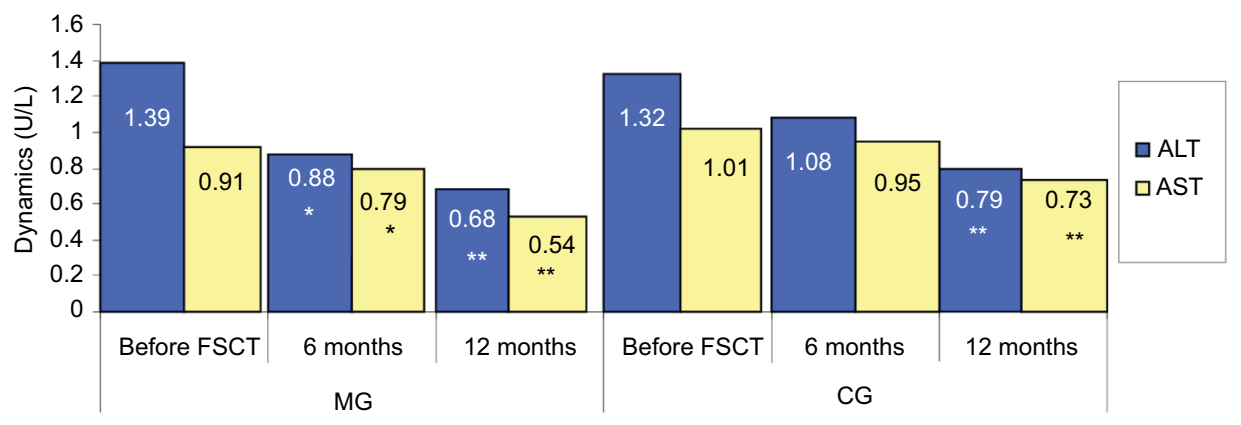

Figure I FSCT effect on serum ALT and AST levels in the patients of the MG and CG.

Note: ${ }^{*} p<0.05$ if compared to the results at baseline and at 6 months after treatment; ${ }^{* *} p<0.05$ if compared to the results at baseline and at 12 months after treatment. Abbreviations: ALT, alanine aminotransferase; AST, aspartate aminotransferase; CG, control group; FSCT, fetal stem cell treatment; MG, main group.

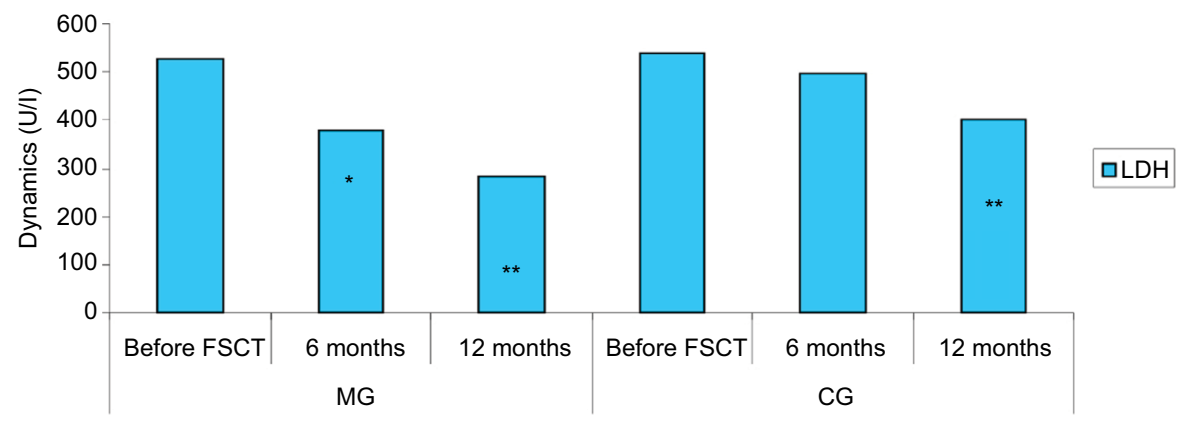

Figure 2 FSCT effect on serum LDH levels in the patients in the MG and CG.

Note: ${ }^{*} p<0.05$ if compared to the results at baseline and at 6 months after treatment; ${ }^{*} p<0.05$ if compared to the results at baseline and at 12 months after treatment. Abbreviations: CG, control group; FSCT, fetal stem cell treatment; LDH, lactate dehydrogenase; MG, main group.

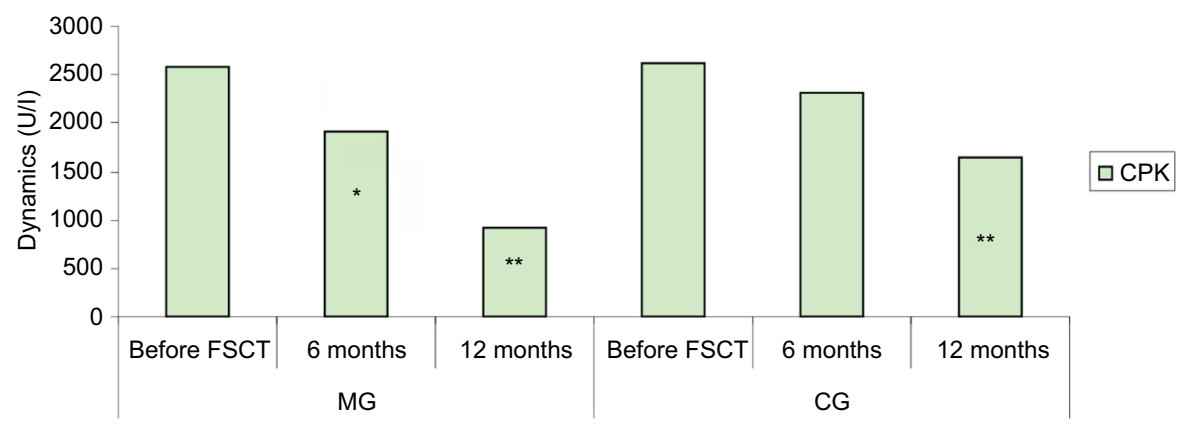

Figure 3 FSCT effect on serum CPK levels in the patients in the MG and CG.

Note: ${ }^{*} p<0.05$ if compared to the results at baseline and at 6 months after treatment; ${ }^{* *} p<0.05$ if compared to the results at baseline and at 12 months after treatment. Abbreviations: CG, control group; CPK< creatine phosphokinase; FSCT, fetal stem cell treatment; MG, main group. 
visualize the intravascular distribution of a superparamagnetic iron oxide contrast agent, and this can therefore be used to accurately show intra-arterial distribution of stem cells in the body. Moreover, high-speed magnetic resonance imaging enables the real-time visualization of cell homing, providing the opportunity for immediate intervention in the case of undesired biodistribution. ${ }^{11}$

In addition, transplanted stem cells are able to systemically migrate within the host, where their homing takes place in order to occupy numerous compartments of muscles, to engraft and differentiate into functional muscle cells which can express dystrophin, or to fuse with myofibrils and restore dystrophin synthesis. ${ }^{12}$ In addition, cell engraftment and homing is increased in the damaged tissues, and FSCs can present a higher potential to engraft compared to adult stem cells. ${ }^{13}$ The capacity of stem cells to migrate and engraft could lead to improvement of respiratory parameters, which were also described during this study. It is unequivocally known that respiratory failure is promoted by restrictive changes in the lungs of patients suffering from SMA-III. Stem cells are able to migrate to the affected areas of the lungs, contribute to regeneration of alveoli, and improve blood circulation within the lung tissue. ${ }^{14}$

\section{Conclusion}

In SMA-III patients, FSCT results in inhibition of disease progression and improvements in different aspects. Some of the key findings in terms of improvement in the patients in this study were as follows:

1. Authors proved the efficacy and safety of FSCs treatment in patients suffering from SMA-III.

2. Improvement of $\mathrm{FVC}$ and $\mathrm{FEV}_{1}$ in patients in the $\mathrm{MG}$ was reported as early as 6 months after FSCT, whereas in the patients of the CG we observed similar improvements only at 12 months after treatment.

3. Significant reduction in the levels of ALT, AST, CPK, and LDH was recorded at 6 months after FSCT among the patients of the MG. The same scores were also significantly reduced in the CG patients at 12 months after treatment.

In order to inhibit fast progression of SMA-III disease and to maintain better life quality, a combined treatment by use of physiotherapy, massage, and respiratory gymnastics can be actively used by the patients.

We do understand that this study involved only a small number of patients. All improvements recorded by the doctors might appear for a definite scope of time only. Therefore, further research and randomized, placebo-controlled studies will be required to characterize all remote benefits for SMA-III patients in complex therapy including FSCs In addition, further studies are necessary to fully understand all mechanisms by which FSCs have an effect on the pathogenesis of SMA-III. Nevertheless, patient-specific FSCT could be regarded as the most effective treatment approach for a definite SMA disease sufferer, introducing a new era within this field of science.

\section{Disclosure}

All authors are members of Cell Therapy Center EmCell, Kyiv, Ukraine. The authors report no other conflicts of interest in this work.

\section{References}

1. Kazakov VM. Clinical molecular and genetic classification of muscular dystrophies (scientific review with comments). Neurol $J$. 2001;3(C):47-52.

2. Yevtushenko SK, Shaymurzin MR, Yevtushenko OS, et al. Early clinical and instrumental diagnostics and therapy for fast and slowly progressive muscular dystrophies and amyotrophias. Int Neurol J. 2007;4(14): $8-12$.

3. Monani UR, Lorson CL, Parsons DW, et al. A single nucleotide difference that alters splicing patterns distinguishes the SMA gene SMN1 from the copy gene SMN2. Hum Mol Genet. 1999;8(7):1177-1183.

4. Faravelli I, Nizzardo M, Comi GP, Corti S. Spinal muscular atrophy-recent therapeutic advances for an old challenge. Nat Rev Neurol. 2015;11(6): 351-359.

5. Hoy SM. Nusinersen: first global statement. Drugs. 2017;77(4):473-479.

6. Gabanella F, Carissimi C, Usiello A, Pellizzoni L. The activity of the spinal muscular atrophy protein is regulated during development and cellular differentiation. Hum Mol Genet. 2005;14(23):3629-3642.

7. Sych N, Klunnik M, ivankova O, et al. Efficacy of fetal stem cells in Duchenne muscular dystrophy therapy. J Neurorestoratol. 2014;2:37-46.

8. Sych NS, Ivankova OV, Klunnyk MO, et al. Fetal stem cells are effective in the treatment of Grade I and II respiratory failure in amyotrophic lateral sclerosis and muscular dystrophy. Transl Neurosci Clin. 2015;1(1):10-16.

9. Bazarova MP. A guide to practical training in clinical laboratory. Kyiv: Vyshcha Shkola. 1981;312.

10. Miller MR, Hankinson J, Brusasco V, et al. Standardisation of spirometry. Eur Respir J. 2005;26(2):319-338.

11. Walczak P, Wojtkiewicz J, Nowakowski A, et al. Real-time MRI for precise and predictable intra-arterial stem cell delivery to the central nervous system. J Cereb Blood Flow Metab. 2017;37(7):2346-2356.

12. Illarioshkin SN, Ivanova-Smolenskaya IA, Markova ED. DNADiagnostics and Genetic Consulting in Neurology (Illarioshkin S.N.), 2002; 78-95.

13. Taylor PA, McElmurry RT, Lees CJ, Harrison DE, Blazar BR. Allogenic fetal liver cells have a distinct competitive engraftment advantage over adult bone marrow cells when infused into fetal as compared with adult severe combined immunodeficient recipients. Blood. 2002;99(5):1870-1872.

14. Kazakov VM. Clinical molecular genetic classification of muscular dystrophies (scientific summary with comments). J Neurol. 2001;3:7-12. 
Journal of Neurorestoratology

\section{Publish your work in this journal}

The Journal of Neurorestoratology is an international, peer-reviewed, open access online journal publishing original research and review articles on the subject of Neurorestoratology. To provide complete coverage of this revolutionary field the Journal of Neurorestoratology will report on relevant experimental research, technological advances, and clinical achievements. The manuscript management system is completely online and includes a very quick and fair peer-review system, which is all easy to use. Visit http://www.dovepress.com/testimonials php to read real quotes from published authors.

Submit your manuscript here: https:/www.dovepress.com/journal-of-neurorestoratology-journal 